\title{
Determination of End Unsaturation in Polyetherpolyols by the Wijs Procedure
}

\author{
Akio MasuI \\ Research Center, Asahi Glass Co., Ltd., 1150, Hazawa-cho, Kanagawa-ku, Yokohama 221, Japan
}

Keywords Polyetherpolyols, Wijs procedure, unsaturation

Polyetherpolyols are widely used as raw materials for the production of polyurethane resin. Both allyl and cis-propenyl end groups are present as byproducts in polyetherpolyols synthesized by the base-catalyzed addition of propyleneoxide to initiator compounds, such as polyfunctional alcohols. ${ }^{1}$ That is, during the course of the addition reaction, a small portion of propyleneoxide acts as an allyl initiator to produce mono-ol of lower molecular weight. Thus, to some extent, the allyl end groups produced in this reaction are thermally rearranged into cis-propenyl end groups in the reactor.

Because such unsaturated mono-ols in polyetherpolyols prevent cross-liknage of the polyurethane, the physical property of the resin is seriously affected by the amount of these byproducts. For determining these unsaturations, mercuric acetate titration has so far been widely used for industrial purposes ${ }^{2,3}$, however, a new method that is less toxic to the environment is required. Since the concentration of olefinic unsaturation in polyetherpolyols is considerably low compared with other unsaturated industrial materials, such as drying oils and fatty compounds, a titration technique using highly reactive iodine-monochloride (the Wijs procedure) ${ }^{4-7}$ was examined.

\section{Experimental}

\section{Samples}

All of the samples analyzed in this work were chosen from experimentally synthesized polyetherpolyols at the Research Center of Asahi Glass Co., Ltd. or industrially produced polyetherpolyols by Asahi Olin Co., Ltd. Propyleneglycol, glycerin and allyl alcohol were used as initiator compounds. Propyleneoxide (PO) was added in the presence of a $\mathrm{KOH}$ catalyst. Some of the samples were subsequently treated with ethyleneoxide (EO) for end-capping to obtain primary polyols.

\section{Reagents and solutions}

Analytical-grade reagents and deionized-distilled water were used throughout the experiments.
The Wijs reagent. ${ }^{8} \quad$ After $9.0 \mathrm{~g}$ of iodine was dissolved in $900 \mathrm{ml}$ of warmed glacial acetic acid, iodine trichloride $\left(\mathrm{ICl}_{3}\right)$ dissolved in $60 \mathrm{ml}$ of glacial acetic acid was added. They were then mixed, cooled and made up to a 11 solution. The Wijs solution was kept in a cool, dark place in a tightly capped bottle.

Sodium thiosulfate standard solution $(0.1 N)$. After $26 \mathrm{~g}$ of sodium thiosulfate $\left(\mathrm{Na}_{2} \mathrm{~S}_{2} \mathrm{O}_{3} \cdot 5 \mathrm{H}_{2} \mathrm{O}\right)$ was dissolved in water and diluted to $11,0.1 \mathrm{~g}$ of sodium carbonate $\left(\mathrm{Na}_{2} \mathrm{CO}_{3}\right)$ was added. The solution was standardized against a potassium iodate $\left(\mathrm{KIO}_{3}\right)$ primary standard as follows: about $40 \mathrm{mg}$ of the $\mathrm{KIO}_{3}$ was weighed into a glass-stoppered $300 \mathrm{ml}$ flask and dissolved in $30 \mathrm{ml}$ of water. Then, $2 \mathrm{~g}$ of KI was added; as soon as this was dissolved, $5 \mathrm{ml}$ of a $2 \mathrm{M} \mathrm{HCl}$ solution was also added. Liberated iodine was titrated immediately with the $\mathrm{Na}_{2} \mathrm{~S}_{2} \mathrm{O}_{3}$ solution, using a starch indicator near to the end point. The normality of the $\mathrm{Na}_{2} \mathrm{~S}_{2} \mathrm{O}_{3}$ solution was calculated as follows:

$$
\text { Normality }=W /(35.67 \times V)
$$

where $W$ is the amount of $\mathrm{KIO}_{3}$ used in $\mathrm{mg}$ and $V$ the volume of $\mathrm{Na}_{2} \mathrm{~S}_{2} \mathrm{O}_{3}$ solution in $\mathrm{ml}$ required for titration of the $\mathrm{KIO}_{3}$.

Potassium iodide solution. Two grams of potassium iodide (KI) was dissolved in $100 \mathrm{ml}$ of water.

Starch indicator solution. After making a homogeneous paste of $10 \mathrm{~g}$ of soluble starch, it was added to $200 \mathrm{ml}$ of boiling water, stirred rapidly, and cooled. About $10 \mathrm{mg}$ of thymol was added as a preservative.

\section{Apparatus}

All titrations were carried out using ordinary laboratory equipment.

\section{Procedure}

A quantity of the sample specimen (ca.5-20 g) was weighed into a glass-stoppered $500 \mathrm{ml}$ flask and dissolved in chloroform. If the unsaturation value falls about 0.07 , for example, the specimen size of $10 \mathrm{~g}$ with $30 \mathrm{ml}$ of chloroform is recommended. 
Table 1 Unsaturation obtained by two methods

\begin{tabular}{lccccc}
\hline \multicolumn{3}{c}{ Polyetherpolyols analyzed } & & & Unsaturation (meq/g) \\
\cline { 1 - 2 } \cline { 5 - 6 } Initiator & Molecular weight & $\begin{array}{c}\text { EO Capping, } \\
\text { wt\% }\end{array}$ & & Wijs procedure & Mercuric acetate procedure \\
\cline { 1 - 1 } Propyleneglycol & 4000 & 23 & & 0.037 & 0.036 \\
Propyleneglycol & 4000 & 23 & & 0.057 & 0.057 \\
Glycerin & 5000 & 0 & & 0.074 & 0.073 \\
Glycerin & 5000 & 0 & & 0.067 & 0.068 \\
Glycerin & 6000 & 5 & & 0.135 & 0.135 \\
Glycerin & 6500 & 0 & & 0.067 & 0.065 \\
Glycerin & 7000 & 15 & & 0.091 & 0.088 \\
Allyl alcohol & 1700 & 0 & & 0.520 & 0.519 \\
\hline
\end{tabular}

The Wijs reagent $(20 \mathrm{ml})$ was added and the flask was stoppered, shaken and allowed to stand in a dark place for $1 \mathrm{~h}$. The flask was occasionally stirred.

A potassium iodide solution $(100 \mathrm{ml})$ was added into the flask. The flask was stoppered, swirled and the released iodine was titrated with a $\mathrm{Na}_{2} \mathrm{~S}_{2} \mathrm{O}_{3}$ solution by adding from the $50 \mathrm{ml}$ buret, with continuous agitation using a starch indicator solution. The titration was completed in the usual manner when both the waterphase and the chloroform-phase become entirely colorless.

Blank determinations were conducted simultaneously by following the same procedure as described, except that no sample was added.

The total unsaturation value (meq/g) was calculated as follows:

\section{Unsaturation value $=(B-V) \times F / 2 S$}

where $B$ is the volume of $\mathrm{Na}_{2} \mathrm{~S}_{2} \mathrm{O}_{3}$ solution in $\mathrm{ml}$ required for titration of the blank and $V$ is that of $\mathrm{Na}_{2} \mathrm{~S}_{2} \mathrm{O}_{3}$ solution in $\mathrm{ml}$ required for titration of the sample, $F$ is the normality of the $\mathrm{Na}_{2} \mathrm{~S}_{2} \mathrm{O}_{3}$ solution, and $S$ is the amount of sample used in $\mathrm{g}$.

The reason why the numerator of the equation is divided by two is as follows. In the mercuric acetate procedure, one acetic acid molecule is released from one $\mathrm{C}=\mathrm{C}$ double bond.

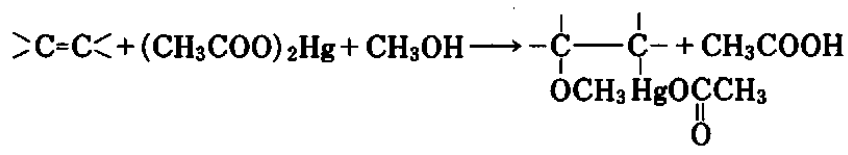

Thus, the unsaturation is expressed with units of "milliequivalent per gram". On the other hand, in the Wijs procedure, one $\mathrm{C}=\mathrm{C}$ double bond reacts with one $\mathrm{ICl}$ molecule, which means a di-equivalent reaction:

\section{Conventional method}

Conventional mercuric acetate titration was also conducted according to ASTM. ${ }^{2}$ The results obtained by both titration methods were compared.

\section{Results and Discussion}

Unsaturation by the Wijs procedure and the conventional mercuric acetate procedure are in good agreement (see Table 1). It is noted that if the samples contain antioxidants, such as BHT (2,6-di-t-butyl-4-methylphenol), the unsaturation obtained by the Wijs procedure becomes slightly higher. For example, the addition of $1000 \mathrm{ppm}$ of BHT to polyetherpolyols increases by about $0.01 \mathrm{meq} / \mathrm{g}$ the unsaturation measure. Therefore, a correction is necessary if the sample contains such additives. It is also noted that since the reaction between BHT and $\mathrm{ICl}$ is relatively slow, the correction value is a variable according to the experimental condition.

Thus, the Wijs procedure gives quite satisfactory results, and the reagents used in the procedure are practically stable. This technique is less toxic to the environment. It is concluded that the Wijs procedure can be an alternative technique to the conventional mercuric acetate procedure.

\section{References}

1. G. J. Dege, R. L. Harris and J. S. MacKenzie, J. Am. Chem. Soc., 81, 3374 (1958).

2. ASTM D2849.

3. JIS K1557-1970.

4. ASTM D460-60.

5. ASTM D1959-85.

6. ASTM D2075-89.

7. ASTM D2078-86.

8. A. Polgár and J. L. Jungnickel, in "Organic Analysis", Vol. 3, pp. 203-386, Interscience, New York, 1956. 